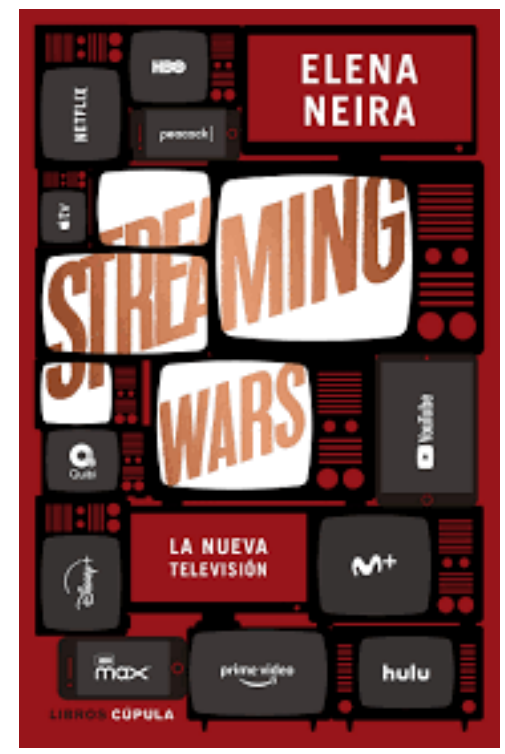

\title{
Streaming wars. La nueva televisión
}

\author{
Elena Neira
}

\author{
Libros Cúpula. Barcelona, 2020, 208 pp. \\ ISBN-13: 978-8448026585
}

\author{
Por: Liza Adriana Higuera Rubio' \\ Recibido: 20-06-2021 - Aceptado: 25-08-2021 \\ https://doi.org/10.26441/RC20.2-2021-R2
}

El sector del entretenimiento que estuvo basado en el uso de la televisión como el eje de la vida cotidiana de las familias en entornos gregarios, se ha trasladado a la elección individual y al hiperconsumo desde las plataformas con contenidos, cuya diversidad crea estímulos constantes en un escenario de ubicuidad e hiperconexión. "Streaming wars. La nueva Televisión" es un libro escrito por Elena Neira, que aborda conceptualmente la evolución, presente y futuro del streaming de cara al cambio de paradigma, las transformaciones, las transiciones y las crisis que han revolucionado la industria cultural del cine y la televisión.

Esta obra hace hincapié en la relevancia de la "libertad" como una de las características del consumo de la nueva televisión y uno de los ejes del cambio paradigmático. "Este libro también quiere ser una guía para comprender hasta qué punto el streaming ha cambiado nuestra forma de ver contenidos, cómo los servicios nos «manipulan» para mantenernos enganchados a sus series, cómo se cuelan en nuestros dispositivos, cómo convierten cada estreno en una necesidad...". Resume Neira.

El libro se compone de tres partes: La nueva televisión, Streaming Wars y ¿Qué contratar? La primera parte hace una amplia revisión de los diferentes tipos, modelos, funcionalidad y servicios que ofrecen las plataformas, cuyo contenido "...circula libremente por internet sin necesidad de un operador". Describe los factores que han intervenido en el surgimiento de la nueva televisión: 'la digitalización', 'la innovación tecnológica' y la 'accesibilidad a Internet'. Neira $(2020,15)$ explica el cambio del soporte físico al digital, con la metáfora del agua, y afirma que "la nueva televisión es líquida" porque puede fluir atemporalmente en los dispositivos tecnológicos usados.

Asimismo, la autora reflexiona sobre la relevancia del smartphone como extensión de la vida cotidiana del usuario. Por ello, la intimidad en la pantalla se convierte en la nueva manera de interactuar con el contenido en el dispositivo móvil.

En el apartado "Bienvenido Mister Netflix", Neira reconoce a esta empresa como la que ha "propiciado las mayores transformaciones del modelo de negocio de los contenidos en internet" (2020, 21). Las series se convertirían en su producto emblemático, y fideliza a los usuarios debido a la cantidad de horas de consumo seguidas.

\footnotetext{
${ }^{1}$ Liza Adriana Higuera Rubio es Magíster en Lingüística Española y Docente de Tiempo Completo del Área de Periodismo de la Universidad de Piura. Ha investigado recientemente sobre el rol de los medios digitales emergentes en contextos de crisis. liza.higuera@udep.edu.pe, https://orcid.org/0000-0003-1322-8728
} 
Cabe destacar que el auge del big data y el uso de los algoritmos como parte de la estrategia de negocio de Netflix sumado al uso de la estructura de videojuego en su plataforma, le han permitido competir con ventaja en la oferta de servicios de contenido por suscripción.

En el capítulo titulado: “Tiempos difíciles para la televisión convencional”, se sintetiza el panorama de la crisis de este modelo de consumo audiovisual desde el hogar. En el pasado aún reciente, las familias se congregaban alrededor de la 'caja mágica' para ver su serie o programa de televisión favoritos. Neira pone en evidencia cómo desde el auge del VSH, el blue-ray y el DVD, hasta llegar a la producción de contenido por demanda han transcurrido tan solo tres décadas. También, se constata en sus razonamientos cómo el nuevo entretenimiento ha transformado al espectador, que prefiere evitar los anuncios publicitarios y organizar su horario de visualización.

Así las cosas, el modelo de negocio de la televisión tradicional sigue utilizando una parrilla de contenidos generalista, lo que se contrapone al servicio de streaming que es "más diverso y de nicho". Asimismo, se observa el traslado del modelo lineal de publicidad a sus páginas web, lo cual las satura de contenido y también dificulta la elección del usuario.

El cuarto capítulo titulado: El ADN de la nueva televisión, hace énfasis en que se debe concebir como parte de una experiencia, y no como un soporte o contenido. La denominada 'caja tonta' hecha para el aburrimiento, ahora se convierte en una máquina más inteligente que sus creadores.

La tercera parte del libro desarrolla el tema de la evolución del negocio global del contenido por demanda, donde se destacan: Netflix, Amazon y HBO. Otras compañías intentan avasallar el escenario del Streaming Wars, el caso de: Disney+, Apple TV, HBO Max y Peacock. Este apartado se basa en el estudio pormenorizado de las estrategias usadas por estas empresas.

"Los Nuevos" es un capítulo que hace referencia a la trayectoria de Disney+, APPLE TV+, HBO Max, Peacock y Quibi, donde se muestra que cada una de estas compañías tiene fortalezas relacionadas con su experiencia en el mercado. Algunas prefieren el uso del algoritmo para conocer los hábitos de sus usuarios y otras están encaminadas a fortalecer la calidad de sus producciones.

Por otra parte, Netflix se prepara para la guerra en el ámbito del Streaming, con estrategias como la creación de contenido original, el uso de storytelling, confianza en el prestigio de la marca, entre otras.

Mientras que Amazon es la segunda empresa con mayor cuota en el mercado. Algunas de sus estrategias son: asegurar el catálogo buscando nuevos clientes, la calidad del producto y la importancia del talento.

La resistencia local es el título del último apartado que hace referencia a cientos de plataformas digitales y extranjeras con las que cuenta el mercado español, por lo que la llegada de las grandes compañías del streaming representa un futuro incierto.

El capítulo: ¿Qué contratar? Plantea recomendaciones generales para saber a qué tipo de servicio de streaming suscribirse, dependiendo de las necesidades del usuario, con la salvedad de que siempre hay contenido digital disponible y gratuito.

Sin duda, "Streaming Wars. La nueva televisión" es un libro exhaustivo en dar explicaciones acerca del origen, los hitos y los cambios en los modelos de negocio de las plataformas dedicadas a prestar servicios de contenido audiovisual mostrando los pros y los contras de cada una. Con seguridad, los académicos del área, al igual que investigadores y alumnos encontrarán en esta obra, un apoyo a la hora de abordar el tema. También para reflexionar frente a los desafíos que traen las nuevas formas de consumo cultural, las narrativas, la interacción con las audiencias abrumadas con la sobreabundancia de contenido y las consecuencias del uso indiscriminado del algoritmo en el comportamiento del usuario. 